\title{
Physical Exercise in Patients with Severe Kidney Disease
}

\author{
G.C. Kosmadakis ${ }^{a} \quad$ A. Bevington ${ }^{b} \quad$ A.C. Smith ${ }^{a} \quad$ E.L.Clapp ${ }^{c} \quad$ J.L. Viana ${ }^{c}$ \\ N.C. Bishop c J. Feehally ${ }^{a, b}$ \\ ${ }^{a}$ The John Walls Renal Unit, Leicester General Hospital, University Hospitals of Leicester NHS Trust and \\ ${ }^{b}$ Department of Infection, Immunity and Inflammation, University of Leicester, Leicester, and 'School of Sport, \\ Exercise and Health Sciences, Loughborough University, Loughborough, UK
}

\section{Key Words}

Exercise $\cdot$ Rehabilitation $\cdot$ Endurance $\cdot$ Resistance $\cdot$ Renal

failure $\cdot$ Haemodialysis $\cdot$ Chronic kidney disease

\begin{abstract}
Patients with advanced chronic kidney disease (CKD), especially those on long-term dialysis, often suffer from muscle wasting and excessive fatigue. It is known that inactivity, muscle wasting and reduced physical functioning are associated with increased mortality in CKD. Known causes include uraemic myopathy and neuropathy, inactivity, and anaemia. Exercise in patients receiving regular dialysis treatment for end-stage renal disease was first introduced 3 decades ago, but is still only offered in a minority of renal units around the world, despite a significant body of evidence to support its use. Work is needed to increase awareness of the potential benefits of increased physical activity for patients with advanced CKD. This review summarizes the mechanisms of exercise intolerance and debility in advanced CKD patients, the methods used for the estimation of functional capacity, the options currently available for exercise training, and their influence on the well-being of this group of patients.

Copyright ๑ 2010 S. Karger AG, Basel
\end{abstract}

\section{Introduction}

The central demographic problem of modern nephrology is the rapid increase in the number of patients with advanced renal disease ultimately requiring renal replacement therapy (RRT). In the UK in the 1980s the annual acceptance rate of new patients for RRT was 20 per million of population but had escalated to 113 per million of population by 2006 . In 2003, 28,037 patients were receiving RRT in the UK, rising to 43,901 by the end of 2006. Whether this rising acceptance rate is being driven by an increase in the prevalence of pre-end-stage chronic kidney disease (CKD) is unknown. The median age of patients on RRT has also increased from 54.3 years in 1998 to 57.1 years in 2006 [1]. Data from the United States Renal Data System show similar trends in the incidence and prevalence of RRT in the USA over the same period.

A growing burden arising from this increase is the poor physical function of this aging patient population, culminating in markedly increased morbidity and mortality, particularly from cardiovascular disease [2]. Patients with end-stage renal disease (ESRD) receiving maintenance haemodialysis (HD) have a considerably lower exercise tolerance, functional capacity, endurance and strength, and more muscle wasting than healthy subjects or patients with less severe CKD who do not yet need RRT $[3,4]$. Physical fitness is also poor in peritoneal di-

Dr. George Kosmadakis

The John Walls Renal Unit, Leicester General Hospital

Gwendolen Rd, Leicester LE5 4PW (UK)

Tel. +44 116258 4132, Fax +441162584764

E-Mail george.kosmadakis@googlemail.com

\begin{tabular}{ll}
\hline KARGER & $@ 2010$ S. Karger AG, Basel \\
Fax +4161306 1234 & \\
$\begin{array}{l}\text { E-Mail karger@karger.ch } \\
\text { www.karger.com }\end{array}$ & $\begin{array}{l}\text { Accessible online at: } \\
\text { www.karger.com/nec }\end{array}$
\end{tabular}


alysis patients, although the infusion of dialysis fluid into the peritoneal cavity does not by itself seem to affect physical capacity [5]. In a large observational study, reduced exercise capacity was found to be associated with poorer survival in ambulatory ESRD patients [6] and the accompanying muscle wasting and changes in body composition are well-established predictors of increased mortality in ESRD [7] and in HD patients [8]. Low levels of physical activity in ESRD can also lead to obesity which, in the context of muscle wasting, is associated with inflammation and is a negative predictor of survival [9]. As shown in a recent minireview in this series, obesity is also a major risk factor for further progression of CKD [10].

Patients with a range of chronic medical conditions other than CKD also suffer from poor physical performance and muscle wasting, and there is mounting evidence of beneficial effects of exercise in these conditions [11-16]. Such conditions include congestive heart failure and coronary artery disease [11], cerebrovascular disease [12], peripheral vascular disease (PVD) [13], chronic obstructive pulmonary disease (COPD) [14], asthma [15] and cancer [16]. This review now describes the potential impact of exercise therapy in advanced CKD, specifically: (1) the major factors leading to poor physical function, (2) the effects of exercise, (3) techniques for measuring aerobic exercise capacity, muscle volume and strength, and physical functioning, 4) practical methods for applying exercise therapy, and (5) the limitations on exercise therapy.

\section{Factors Leading to Poor Physical Function in CKD}

\section{Inactivity}

In patients with CKD and ESRD the 3 broad factors of kidney failure itself (with its associated malaise), side effects of the RRT, and worsening co-morbidity combine to discourage physical activity. Inactivity is therefore regarded as a major factor leading to impaired physical condition, reduced exercise capacity and ultimately muscle wasting [17]. HD patients are significantly less active than sedentary age-matched controls [18] and their physical activity declines by up to $3.4 \%$ each month after initiation of dialysis [19]. Lack of physical activity is a negative prognostic factor for survival in $\mathrm{HD}$; sedentary $\mathrm{HD}$ patients have a $62 \%$ greater mortality risk at 1 year compared to those who are more active [20]. Mortality risks are greater for those with severe limitations in moderate physical activities compared with those reporting minimal or no limitations, and are lower in patients who exercise regularly [21].
Functional and Structural Muscle Abnormalities

Advanced CKD is associated with protein wasting (cachexia), especially affecting skeletal muscle, both as a result of impaired protein synthesis [22] and increased protein degradation [23]. There is a gradual increase in muscle wasting as kidney function deteriorates towards the need for RRT [22], and defective protein metabolism is observed in those treated with regular dialysis [23] suggesting that both renal failure itself and the dialysis process contribute to this catabolic state $[24,25]$. Specifically HD has been shown to promote muscle and whole body protein degradation $[24,26]$. Chronic metabolic acidosis (which occurs in nearly all patients with advanced CKD) contributes to this increased protein degradation [23] by activation of the ubiquitin-proteasome pathway [27], possibly initiated by impairing the transport and utilization of amino acids [28]. Even though the muscle atrophy that arises from this protein wasting is a significant contributor to reduced strength and reduced ability to generate force (myopathy), it is important to note that impaired activation of the motor neurons by the central nervous system (central activation failure) also contributes to the problem [29].

Patients on dialysis also have an intrinsic functional defect in mitochondrial energy metabolism in their skeletal muscle [30], which means that, after exercise, they have lower intramuscular phosphocreatine (PCr) and $\mathrm{pH}$, and a higher inorganic phosphate/PCr ratio than is observed in control subjects $[4,30]$. This deficient mitochondrial energy metabolism means that the rate of production of high energy organophosphorus compounds (ATP and $\mathrm{PCr}$ ) following exercise is impaired, leading to slower functional recovery from a bout of muscle contraction. These patients also have increased lipid peroxidation (an indicator of increased production of toxic free radicals from mitochondria) [31], lower levels of muscle total carnitine, which is a cofactor for the transport of long-chain fatty acid fuels into the mitochondria [32], and impaired extrarenal potassium regulation which may contribute to early muscle fatigue during exercise [33].

At structural level, measurements performed in nonlocomotor muscles (to avoid the potential confounding effect of inactivity) have shown significant atrophy of all muscle fibre types, and reduced fibre capillarization in advanced CKD compared to healthy controls [34]. Skeletal muscles from patients with CKD show multiple structural abnormalities including fibre splitting and degeneration and increased numbers of lipid droplets by light microscopy, and mitochondrial changes, Z-band degeneration, myofilament loss, and accumulation of intracellular glycogen by electron microscopy [35]. 


\section{Inflammation}

While renal failure itself is a pro-inflammatory state, this problem is further aggravated by HD. Elevated circulating concentrations of inflammatory markers, notably C-reactive protein and interleukin-6 (IL-6), are observed in HD patients and show an inverse correlation with thigh muscle mass [36]. Net output of IL-6 from muscle during HD is thought to be a particularly important stimulus for muscle protein wasting [25]. In part, this may arise from the resulting resistance to the anabolic effects of insulin or insulin-like growth factors [37] that occurs in the skeletal muscle of patients with advanced CKD; resistance which recent studies in mice suggest arises from the action of IL-6 [38].

\section{Blood Flow and Anaemia}

Dialysis patients at rest do not show significant differences in their muscle blood flow compared to control subjects; nevertheless, their muscle blood flow rises significantly less than in control subjects during both submaximal and maximal exercise [39]. Patients with advanced $\mathrm{CKD}$ are anaemic [40] as a result of multiple factors (including inability to produce erythropoietin, and reduced erythrocyte survival). The degree of anaemia in these patients is associated with reduced aerobic and anaerobic exercise capacity [41]. Increases in haemoglobin concentration following erythropoietin therapy correlate with improvements in aerobic performance [42], although full exercise tolerance is not regained after restoring normal or near-normal haemoglobin concentrations [43].

\section{The Effects of Exercise}

In dialysis patients, both aerobic (endurance) exercise and resistance exercise have demonstrable effects. A comprehensive tabulation of such studies, including the type of exercise, the timing relative to the dialysis session and the resulting effects on physiological function, has been published [44]. Intradialytic aerobic exercise leads to a significant increase in aerobic exercise capacity and duration of exercise [45]. In a systematic review of 29 clinical trials, it was shown that physical condition was significantly improved following the use of aerobic training [44]. Resistance training increases strength and functional capacity in patients with advanced CKD (shown by increases in the peak torque of quadriceps muscle, the distance covered during a 6-min walk test, maximal walking speed, and improved performance in a sit-tostand test [46]. (These functional tests are explained fur- ther in the section on 'The assessment of exercise capacity'.) Further specific benefits of exercise are discussed below.

\section{Muscle Structure and Function}

Histologically, resistance training in advanced CKD has been shown to lead to skeletal muscle hypertrophy, demonstrated by reduced numbers of atrophic fibres, and significant increases in type I, type IIa and type IIx muscle fibre cross-sectional areas [47]. After an aerobic exercise programme, muscle strength, power and fatigability in patients with advanced CKD improved significantly, indicating that aerobic exercise exerted effects comparable with those of resistance training. Such effects on muscle are not a general feature of aerobic exercise but are thought to be manifested in advanced CKD because of the generally poor initial physical state of the patients and their consequent large potential for improvement [48].

\section{Cardiac Function}

After 6 months of supervised aerobic training there were significant increases in ejection fraction (by $14 \%$ compared to the pretraining levels), in systolic volume index (by 14\%) and in cardiac output index (by 73\%) compared to an unsupervised group and control non-exercising patients with advanced CKD [49]. Exercise training in these patients caused favourable left ventricular functional adaptations, increased cardiac vagal activity, decreased sympathetic overactivity at rest and reduced the incidence of cardiac arrhythmias [50].

\section{Blood Pressure and Other Cardiovascular Risk Factors}

An intradialytic aerobic exercise programme with exercise bicycles in HD patients was associated with significant reduction in intra- and interdialytic systolic and diastolic blood pressure [51], and 4 months of aerobic training in a group of predialysis patients led to a significant reduction of systolic and diastolic blood pressure. The positive effect was reversed completely 2 months after training ceased [52]. The reduction in the blood pressure can lead to a significant reduction in the number of prescribed antihypertensive drugs with a reported cost saving in one study of 885 USD per patient per year [53]. Similar beneficial effects on blood pressure control have been reported in other studies of patients with advanced CKD $[54,55]$ but this was not observed in an early study in the maintenance HD patients [56], possibly because of poor compliance with the exercise programme.

Aerobic exercise training in patients with advanced CKD also reduced very low-density lipoprotein and tri- 
glyceride levels and increase high-density lipoprotein levels [57]. It also improved arterial stiffness, an effect that had reversed by 1 month after training had ceased [58].

\section{Glycaemic Control and Insulin Resistance}

In view of the high proportion of CKD patients who also have diabetes mellitus, an important consideration is whether exercise has any beneficial effect on control of blood glucose. A meta-analysis of 103 studies in type 2 diabetes demonstrated significant improvement in glycaemic control [59]. A similar analysis has not been performed specifically in diabetic CKD patients, but aerobic exercise has been reported to improve insulin resistance in patients with advanced CKD [57], although a more recent study failed to detect this [58].

\section{HD Efficiency}

Two studies have shown a significant increase in HD efficiency with intradialytic exercise [60, 61]. In a 5-month aerobic exercise programme during the $\mathrm{HD}$ session, a significant (11\%) increase in dialysis efficiency expressed as $\mathrm{SpKt} / \mathrm{V}$ was detected at the end of the 1st month, and persisted (18-19\% increase) for the duration of the study [60]. After an HD session, urea, creatinine, potassium and uraemic toxins are slowly transferred from the relatively poorly perfused tissues (especially inactive muscles) to the circulation, giving rise to a postdialysis 'rebound' of the concentrations in circulation. A single bout of exercise reduced the rebound of urea, creatinine and potassium, possibly because of increased perfusion of skeletal muscle [62]. Increased dialytic removal of phosphate achieved with intradialytic exercise may also improve subsequent control of serum phosphate which is often a challenging goal for dialysis patients [63]. A possible contributor to these beneficial effects on potassium and phosphate is the shift of these ions from the intracellular compartment into muscle interstitial fluid that occurs during exercise [64]. Furthermore, regular handgrip training increased the diameters of forearm vessels and improved endotheliumdependent vasodilatation, an effect that can be beneficial before the creation of vascular access for HD [65].

\section{Psychological Adaptations, Quality of Life and Nutrition}

Beck's Depression Index was decreased after an aerobic training programme in patients with various levels of advanced CKD [66], and in HD patients undergoing an intradialytic exercise programme [67]. The most severely depressed patients had the greatest beneficial effects from exercise training, in parallel to significant improvements in quality of life parameters [66]. In other studies, exercise programmes improved anxiety symptoms as well as the physical and mental health scores of the SF-36 quality of life scale $[61,68]$; appetite as well as calorie and protein intake were increased in patients with advanced CKD on HD throughout an aerobic exercise programme performed during the HD session [69].

\section{The Assessment of Exercise Capacity: Measuring Aerobic Exercise Capacity, Muscle Volume and Strength, and Physical Functioning}

Before starting exercise therapy, patients are evaluated to define their suitability for exercise and to tailor individualized exercise prescriptions. Subsequent monitoring is also required to assess the effectiveness of the therapy. Evaluation methods range from self-reported questionnaires to rigorous laboratory measures [reviewed in 70]. The principal methods are summarized below.

\section{Exercise Tolerance Tests}

The gold standard test for aerobic capacity is the $\mathrm{VO}_{2 \text { max }}$ test measuring the maximal amount of oxygen that can be consumed in response to increasing levels of exercise. In deconditioned patients with limited ability to exercise, this test can be difficult to perform satisfactorily, so the $\mathrm{VO}_{2}$ peak test is substituted. This measures the highest possible oxygen consumption in a symptom-limited test. Exercise duration, $\mathrm{VO}_{2 \text { max }}$ or $\mathrm{VO}_{2 \text { peak, }}$ minute ventilation, maximum work rate, acid-base status, blood lactate and carbon dioxide production can all be measured during an exercise test on a treadmill or cycle ergometer [71]. Less than 50\% of dialysis patients are initially able to perform such an exercise test, and those who can complete it may achieve only $57 \pm 20 \%$ of age- and gender-predicted values [72]

\section{Functional Capacity Tests}

Tests regularly used to assess the effects of exercise programmes in CKD patients are the 6-min walk test [73] and sit-to-stand tests (STS). STS5 (the time taken to complete 5 sit-to-stand-to-sit cycles) is a surrogate measure of muscle power and STS60 (number of sit-to-stand-to-sit cycles in $60 \mathrm{~s}$ ) is a surrogate measure of muscular endurance [3]. Although widely used, these tests have not been fully validated in CKD patients. In contrast the North Staffordshire Royal Infirmary walk test (NSRI walk), a combination of walking, stair climbing and descending, has been validated in non-anaemic maintenance dialysis 
patients [74] and has been found to correlate with $\mathrm{VO}_{2}$ peak . It is therefore considered to be a good proxy measure.

\section{Neuromuscular Function Tests}

Muscle strength is usually measured as peak force by isokinetic dynamometry [75] and peak torque [76], and absolute muscle strength using 1 repetition maximum [77] (the maximum weight that can be lifted in a single repetition of a given exercise).

\section{Muscle Composition and Structure}

A cross-sectional area of muscle and fat can be measured from a standardized multislice computed tomography or magnetic resonance imaging scan of a section of the thigh. The changes in fat and muscle volume in this section are indicators of the relative changes in the proportion of fat and muscle volume in the whole body [78]. Alternative methods for estimating composition changes after an exercise programme are measurements of bio-impedance [51] and dual energy x-ray analysis scanning [79]. Muscle biopsies can also be taken from the vastus lateralis or the median portion of the gastrocnemius muscle before and after an exercise rehabilitation programme and be examined for morphometric changes (e.g. the proportion of each muscle fibre type and the muscle fibre area) $[77,80]$ and metabolic changes (e.g. glycogen accumulation) [47].

\section{Practical Methods for Applying Exercise Therapy}

\section{Recommendations}

The recently published UK National Institute for Health and Clinical Excellence (NICE) guidelines for early identification and management of CKD in adults in primary and secondary care include a recommendation to 'encourage people with CKD to take exercise' [81]. In spite of mounting evidence of beneficial effects of exercise in CKD, there are currently no specific exercise guidelines for this population. However, the exercise data in CKD (reviewed above) and current recommendations for healthy people and other chronic disease groups can be used for guidance. For example, Johansen [82] suggested that the recommendations for older adults (65 years and above) and adults aged 50-64 years with clinically significant chronic conditions and/or functional limitations, published in 2007 by the American College of Sports Medicine and the American Heart Association [83], can be applied to patients with advanced CKD. In practice this means that patients for whom exercise is not contraindicated should be instructed to start a routine of physical activity that is appropriate to their individual level of fitness, and safe for their clinical condition. The training regimen should include aerobic, resistance and flexibility activities. Aerobic exercise training should build up to at least $30 \mathrm{~min}$ of moderate intensity exercise on 5 days per week using a gradual approach. For the severely deconditioned patients it may be necessary to initiate exercise at a lower intensity, to accumulate multiple bouts of exercise of shorter duration (about $10 \mathrm{~min}$ ) rather than a single continuous bout and/or to exercise on fewer days per week. Resistance exercise training should also follow a gradual approach and be performed at least twice per week on non-consecutive days and include exercises for the major muscle groups. Flexibility exercises should preferably be performed on all days that aerobic and resistance training is performed.

\section{Monitoring and Tailoring Exercise Therapy}

The rating of perceived exertion using the Borg scale is recommended for controlling the intensity of training [52]. The rating of perceived exertion is a subjective feeling scale that allows the patient to report the perceived intensity of aerobic exercise [84]. For CKD patients, a suitable exercise intensity is $12-16$ on the Borg scale [84]. At moderate exercise intensity like this, significant improvements in exercise capacity occur, but may be manifested only slowly (typically after about 12 weeks) [45].

In view of local variation in treatment regimes, and variation in co-morbidities, exercise prescriptions for $\mathrm{HD}$ and peritoneal dialysis patients need to be tailored individually [85]. Three basic methods of exercise programme delivery have been applied in patients with advanced CKD: (1) a supervised outpatient programme in a rehabilitation centre, (2) a home exercise rehabilitation programme, and (3) exercise during the HD session (intradialytic) [50, 60].

In terms of ensuring the prescribed intensity and duration of exercise, the supervised outpatient programme is the most effective, but it is associated with the highest dropout rates [86]. For intradialytic exercise, it is safer to train during the first $2 \mathrm{~h}$ of the HD session because, after $2 \mathrm{~h}$ of dialysis, shifting of fluid from the microvasculature to the interstitium during exercise can cause a rapid reduction in relative blood volume [87] with accompanying cardiovascular decompensation which may preclude further exercise.

Exercise programmes have been combined successfully with other therapeutic measures. In one study, 79 HD patients followed a programme of resistance training with or without anabolic steroids. The steroids signifi- 
cantly increased lean body mass with an additive effect on top of that of resistance exercise alone [88]. In another study Pupim et al. [89] demonstrated that intradialytic parenteral nutrition combined with aerobic exercise increased protein synthesis and reduced the rate of proteolysis significantly more than intradialytic parenteral nutrition alone.

\section{Limitations on Exercise Therapy}

Even though exercise programmes for patients with advanced CKD were first introduced 3 decades ago [90] their use in the care of people with advanced kidney disease is still not widespread. This is in spite of positive achievements with therapeutic exercise in other chronic disease settings, notably in COPD [91]. One limitation is that, even when such programmes are available, the uptake by CKD patients is low. A likely contributor is that the exercise protocols currently available have often been developed for research studies and are therefore unsuitable for many chronically sick CKD patients with significant co-morbid conditions which need to be monitored. The dropout rate from such research studies can be high: between 30 and $50 \%$ of participants may abandon the exercise depending on the type of exercise offered. For example, out of 34 patients initially recruited for a study of the effect of 6 months of aerobic training on a cycle ergometer, 18 managed to complete the exercise programme and, of these, 2 failed to show any detectable improvement in $\mathrm{VO}_{2}$ peak after training [92]. The equally important issue of the rate of relapse of patients into an inactive lifestyle at the end of an exercise research programme has not been studied intensively, but it has been reported that increased activity persisted approximately 19 months after the programme ended in 9 out of $13 \mathrm{HD}$ patients who completed a 6-month walking exercise study [93].

It is important also to consider why many renal units offer no exercise therapy at all. This is not a reflection of adverse events in CKD patients during exercise. These are rare provided that patients with clear contraindications for exercise are excluded, i.e. unstable hypertension, potentially lethal arrhythmias (including sustained ventricular tachycardia or atrial fibrillation), recent myocardial infarction, unstable angina, active liver disease, uncontrolled diabetes mellitus, advanced cerebral or PVD, and persistent hyperkalaemia before dialysis [94]. Data from the UK Renal Registry [95] indicate that the frequency of such potentially disqualifying co-morbidities reported in incident RRT patients in the UK in the period
2002-2007 was $2.6 \%$ for recent ( $<3$ months) myocardial infarction, $15.3 \%$ for angina, 2.3\% for liver disease, $29.1 \%$ for diabetes, and $9.8 \%$ for cerebrovascular disease. Furthermore, $7.6 \%$ had reported claudication, $3.1 \%$ had ischaemic/neuropathic ulcers, $3.3 \%$ had received angioplasty/vascular graft, and $1.8 \%$ were amputees. Assessing the total percentage of disqualified patients from these figures is complicated by the fact that more than one of these co-morbidities may be present in a given patient, but it should be noted that $47.6 \%$ of the patients in this study had no reported co-morbidity. In principle, therefore, at least half of the patient population approaching RRT is eligible for carefully designed exercise therapy combining aerobic and resistance training in the appropriate frequency and intensity. Most of the remainder seem to have clear indications for cardiovascular rehabilitation.

It is important to emphasize that age per se is not a disqualifying factor and that beneficial effects of exercise to reverse age-related sarcopenia are observable even in the frail elderly [reviewed in 96]. However, an important age-related limitation is that disqualifying co-morbidities increase in frequency with age: for example in the UK Renal Registry data [see fig. 6.3 in 95] the prevalence of PVD amongst incident patients starting RRT in the 6574 age group was twice that in the 45-54 age group, and a numerically similar effect of age was observed for other co-morbidities [95]. Similar limitations on exercise and physical activity associated with age and PVD have been described in patients with ESRD in the USA [97] with PVD prevalence rates ranging from 17 to $48 \%$, depending on the ESRD population studied and the diagnostic methods used [98]. The high prevalence (6\%) and incidence ( 2.0 events/100 patient-years at risk) of amputation in HD patients [99] also shows a marked dependence on increasing age [100].

Even though the definition of 'adverse events' varies between the published trials, these have reported few clinical complications. A meta-analysis showed that the commonest, and rather rare, complication in patients exercising during dialysis is hypotension [44]. In an intradialytic exercise programme in Germany, after more than 50,000 individual exercise sessions, the complications were merely some cases of leg cramps, with no severe cardiovascular complications [101]. This conclusion is reinforced by the results of another programme in North Staffordshire, UK: after more than 4,000 individual intradialytic exercise sessions and over 300 peak exercise tests, there was only 1 case of clinically severe autonomic dysregulation [101]. Diabetic patients may have an increased risk of such autonomic dysregulation [102] 
but, in a group of African-American men identified as at increased risk of diabetes, the long-term effect of resistance exercise was shown to be suppression of autonomic dysregulation [103]. Furthermore, even though patients with renal failure frequently present with co-morbidities such as coronary artery disease, cerebrovascular disease, PVD, COPD, and cancer $[1,95]$, and these may contribute to physical inactivity, these do not necessarily exclude the patients from appropriate exercise programmes. Indeed, such programmes have been shown to be beneficial in each of these co-morbid conditions [11-16].

\section{Conclusions}

While there are still no large randomized controlled trials evaluating the survival benefits of exercise, in our opinion, the evidence reviewed above justifies the regular use of exercise programmes in patients with advanced CKD. The correlation of increased mortality with low physical activity, low muscle mass and reduced physical functioning provides a clear rationale for exercise in this group of patients. It should be emphasized that the most frail and incapacitated patients are probably those most in need of physical rehabilitation as a part of their clinical care. Furthermore, there are likely to be significant gains for healthcare systems, by reducing the collateral costs of CKD patients who, because of deconditioning, require assisted transport and interventions by nurses, physiotherapists and other staff to improve mobility, and have an increased risk of falls and associated complications. Such cost savings may in the long term overcome the financial limitations which tend to impede the introduction of exercise as a routine measure in renal units.

There is clearly a pressing need for high-quality grade A evidence from randomized controlled trials in this field to settle the question of whether physical inactivity causes increased mortality in these patients or is just an indicator of poor general condition that increases mortality risk. The importance of this question can only increase in view of the rising incidence of CKD.

\section{Acknowledgement}

The authors gratefully acknowledge support for this work from Kidney Research UK (GRANT REF RP33/1/2007).

\section{References}

1 UK Renal Registry: 9th Annual Report 2006. Bristol, UK Renal Registry, 2006.

-2 Shlipak MG, Fried LF, Cushman M, Manolio TA, Peterson D, Stehman-Breen C, Bleyer A, Newman A, Siscovick D, Psaty B: Cardiovascular mortality risk in chronic kidney disease: comparison of traditional and novel risk factors. JAMA 2005;293:1737-1745.

-3 McIntyre CW, Selby NM, Sigrist M, Pearce LE, Mercer TH, Naish PF: Patients receiving maintenance dialysis have more severe functionally significant skeletal muscle wasting than patients with dialysis-independent chronic kidney disease. Nephrol Dial Transplant 2006;21:2210-2216.

-4 Johansen KL, Doyle J, Sakkas GK, KentBraun JA: Neural and metabolic mechanisms of excessive muscle fatigue in maintenance hemodialysis patients. Am J Physiol Regul Integr Comp Physiol 2005;289:805813.

$\checkmark 5$ Beasley CR, Smith DA, Neale TJ: Exercise capacity in chronic renal failure patients managed by continuous ambulatory peritoneal dialysis. Aust NZ J Med 1986;16:5-10.

-6 Sietsema KE, Amato A, Adler SG, Brass EP: Exercise capacity as a predictor of survival among ambulatory patients with end-stage renal disease. Kidney Int 2004;65:719-724.
Stenvinkel P, Barany P, Chung SH, Lindholm $\mathrm{B}$, Heimbürger O: A comparative analysis of nutritional parameters as predictors of outcome in male and female ESRD patients. Nephrol Dial Transplant 2002;17:12661274 .

-8 Beddhu S, Pappas LM, Ramkumar N, Samore M: Effects of body size and body composition on survival in hemodialysis patients. J Am Soc Nephrol 2003; 14:2366-2372.

9 Honda H, Qureshi AR, Axelsson J: Obese sarcopenia in patients with end-stage renal disease is associated with inflammation and increased mortality. Am J Clin Nutr 2007;86: 633-638.

10 Ting SM, Nair H, Ching I, Taheri S, Dasgup ta I: Overweight, obesity and chronic kidney disease. Nephron Clin Pract 2009;112:121127.

11 Joshi SB: Exercise training in the management of cardiac failure and ischaemic heart disease. Heart Lung Circ 2007;16:83-87.

12 Pang MY, Eng JJ, Dawson AS, Gylfadóttir S: The use of aerobic exercise training in improving aerobic capacity in individuals with stroke: a meta-analysis. Clin Rehabil 2006, 20:97-111.

13 Bulmer AC, Coombes JS: Optimising exercise training in peripheral arterial disease. Sports Med 2004;34:983-1003.
14 Zuwallack R: The nonpharmacologic treatment of chronic obstructive pulmonary disease: advances in our understanding of pulmonary rehabilitation. Proc Am Thorac Soc 2007;4:549-553.

15 Ram FS, Robinson SM, Black PN, Picot J: Physical training for asthma. Cochrane Database Syst Rev 2005;19:CD001116.

16 Knobf MT, Musanti R, Dorward J: Exercise and quality of life outcomes in patients with cancer. Semin Oncol Nurs 2007;23:285296.

17 Tawney KW, Tawney PJ, Kovach J: Disablement and rehabilitation in end-stage renal disease. Semin Dial 2003;16:447-452.

18 Johansen KL, Chertow GM, Ng AV: Physical activity levels in patients on hemodialysis and healthy sedentary controls. Kidney Int 2000;57:2564-2570.

19 Johansen KL, Kaysen GA, Young BS, Hung AM, da Silva M, Chertow GM: Longitudinal study of nutritional status, body composition, and physical function in hemodialysis patients. Am J Clin Nutr 2003;77:842-846.

20 O'Hare AM, Tawney K, Bacchetti P, Johansen K: Decreased survival among sedentary patients undergoing dialysis: results from the dialysis morbidity and mortality study wave 2. Am J Kidney Dis 2003;41:447-454. 
-21 Stack AG, Molony DA, Rives T, Tyson J, Murthy BV: Association of physical activity with mortality in the US dialysis population. Am J Kidney Dis 2005;45:690-701.

22 Adey D, Kumar R, McCarthy JT, Nair KS: Reduced synthesis of muscle proteins in chronic renal failure. Am J Physiol Endocrinol Metab 2000;278:219-225.

-23 Graham KA, Reaich D, Channon SM, Downie S, Goodship TH: Correction of acidosis in hemodialysis decreases whole-body protein degradation. J Am Soc Nephrol 1997;8: 632-637.

24 Raj DS, Adeniyi O, Dominic EA: Amino acid repletion does not decrease muscle protein catabolism during hemodialysis. Am J Physiol Endcrinol Met 2007;292:1534-1542.

25 Raj DS, Moseley P, Dominic EA: Interleukin- 6 modulates hepatic and muscle protein synthesis during hemodialysis. Kidney Int 2008;73:1054-1061.

26 Ikizler TA, Pupim LB, Brouillette JR: Hemodialysis stimulates muscle and whole body protein loss and alters substrate oxidation. Am J Physiol Endocrinol Metab 2002;282: 107-116.

27 Rajan V, Mitch WE: Ubiquitin, proteasomes and proteolytic mechanisms activated by kidney disease. Biochim Biophys Acta 2008; 1782:795-799.

-28 Evans K, Nasim Z, Brown J, Clapp E, Amin A, Yang B, Herbert TP, Bevington A: Inhibition of SNAT2 by metabolic acidosis enhances proteolysis in skeletal muscle. J Am Soc Nephrol 2008;19:2119-2129.

- 29 Johansen KL, Shubert T, Doyle J, Soher B, Sakkas GK, Kent-Braun JA: Muscle atrophy in patients receiving hemodialysis: effects on muscle strength, muscle quality, and physical function. Kidney Int 2003;63:291-297.

-30 Kemp GJ, Crowe AV, Anijeet HK: Abnormal mitochondrial function and muscle wasting, but normal contractile efficiency, in haemodialysed patients studied non-invasively in vivo. Nephrol Dial Transplant 2004;19: 1520-1527.

-31 Leaf DA, Kleinman MT, Deitrick RW: The effects of exercise on markers of lipid peroxidation in renal dialysis patients compared with control subjects. Am J Med Sci 2004; 327:9-14.

32 Hiatt WR, Koziol BJ, Shapiro JI, Brass EP: Carnitine metabolism during exercise in patients on chronic hemodialysis. Kidney Int 1992;41:1613-1619.

- 33 Sangkabutra T, Crankshaw DP, Schneider C: Impaired $\mathrm{K}^{+}$regulation contributes to exercise limitation in end-stage renal failure. Kidney Int 2003;63:283-290

- 34 Sakkas GK, Ball D, Mercer TH, Sargeant AJ, Tolfrey K, Naish PF: Atrophy of non-locomotor muscle in patients with end-stage renal failure. Nephrol Dial Transplant 2003; 18 : 2074-2081.
35 Diesel W, Emms M, Knight BK: Morphologic features of the myopathy associated with chronic renal failure. Am J Kidney Dis 1993; 22:677-684

36 Kaizu Y, Ohkawa S, Odamaki M: Association between inflammatory mediators and muscle mass in long-term hemodialysis patients. Am J Kidney Dis 2003;42:295-302.

37 Siew ED, Pupim LB, Majchrzak KM, Shintani A, Flakoll PJ, Ikizler TA: Insulin resistance is associated with skeletal muscle protein breakdown in non-diabetic chronic hemodialysis patients. Kidney Int 2007;71: 146-152.

38 Zhang L, Du J, Hu Z, Han G, Delafontaine P, Garcia G, Mitch WE: IL-6 and serum amyloid A synergy mediates angiotensin II-induced muscle wasting. J Am Soc Nephrol 2009;20:604-612.

39 Bradley JR, Anderson JR, Evans DB, Cowley AJ: Impaired nutritive skeletal muscle blood flow in patients with chronic renal failure. Clin Sci (Lond) 1990;79:239-245.

40 Erslev AJ, Besarab A: Erythropoietin in the pathogenesis and treatment of the anemia of chronic renal failure. Kidney Int 1997;51: 622-630.

41 Mayer G, Thum J, Graf H: Anaemia and reduced exercise capacity in patients on chronic haemodialysis. Clin Sci (Lond) 1989;76: 265-268.

42 Painter P, Moore GE: The impact of recombinant human erythropoietin on exercise capacity in hemodialysis patients. Adv Ren Replace Ther 1994;1:55-65.

43 Suzuki M, Tsutsui M, Yokoyama A, Hirasawa Y: Normalization of hematocrit with recombinant human erythropoietin in chronic hemodialysis patients does not fully improve their exercise tolerance abilities. Artif Organs 1995;19:1258-1261.

44 Cheema BSB, Fiatarone Singh MA: Exercise training in patients receiving maintenance hemodialysis: a systematic review of clinical trials. Am J Nephrol 2005;25:352-364.

45 Konstantinidou E, Koukouvou G, Kouidi E, Deligiannis A, Tourkantonis A: Exercise training in patients with end-stage renal disease on hemodialysis: comparison of three rehabilitation programs. J Rehabil Med 2002; 34:40-45.

46 Headley S, Germain M, Mailloux P: Resistance training improves strength and functional measures in patients with end-stage renal disease. Am J Kidney Dis 2002;40:355364.

47 Kouidi E, Albani M, Natsis K: The effects of exercise training on muscle atrophy in haemodialysis patients. Nephrol Dial Transplant 1998;13:685-699.

48 Storer TW, Casaburi R, Sawelson S, Kopple JD: Endurance exercise training during haemodialysis improves strength, power, fatigability and physical performance in maintenance haemodialysis patients. Nephrol Dial Transplant 2005;20:1429-1437.
49 Deligiannis A, Kouidi E, Tassoulas E, Gigis P, Tourkantonis A, Coats A: Cardiac effects of exercise rehabilitation in hemodialysis patients. Int J Cardiol 1999;70:253-266.

50 Kouidi EJ: Central and peripheral adaptations to physical training in patients with end-stage renal disease. Sports Med 2001;31: 651-665.

51 Anderson JE, Boivin MR Jr, Hatchett L: Effect of exercise training on interdialytic ambulatory and treatment-related blood pressure in hemodialysis patients. Ren Fail 2004; 26:539-544.

52 Boyce ML, Robergs RA, Avasthi PS: Exercise training by individuals with predialysis renal failure: cardiorespiratory endurance, hypertension, and renal function. Am J Kidney Dis 1997;30:180-192.

53 Miller BW, Cress CL, Johnson ME, Nichols $\mathrm{DH}$, Schnitzler MA: Exercise during hemodialysis decreases the use of antihypertensive medications. Am J Kidney Dis 2002;39: 828-833.

54 Pechter U, Ots M, Mesikepp S, Zilmer K, Kullissaar T, Vihalemm T, Zilmer M, Maaroos, J: Beneficial effects of water-based exercise in patients with chronic kidney disease. Int J Rehab Res 2003;26:153-156.

55 Painter PL, Nelson-Worel JN, Hill MM, Thornbery DR, Shelp WR, Harrington AR, Weinstein $\mathrm{AB}$ : Effects of exercise training during hemodialysis. Nephron 1986;43:8792.

56 Shalom R, Blumenthal JA, Williams RS, McMurray RG, Dennis VW: Feasibility and benefits of exercise training in patients on maintenance dialysis. Kidney Int 1984;25: 958-963.

57 Goldberg AP, Geltman EM, Gavin JR 3rd: Exercise training reduces coronary risk and effectively rehabilitates hemodialysis patients. Nephron 1986;42:311-316.

58 Mustata S, Chan C, Lai V, Miller JA: Impact of an exercise program on arterial stiffness and insulin resistance in hemodialysis patients. J Am Soc Nephrol 2004;15:27132718 .

59 Conn VS, Hafdahl AR, Mehr DR, LeMaster JW, Brown SA, Nielsen PJ: Metabolic effects of interventions to increase exercise in adults with type 2 diabetes. Diabetologia 2007;50: 913-921.

60 Parsons TL, Toffelmire EB, King-VanVlack $\mathrm{CE}$ : Exercise training during hemodialysis improves dialysis efficacy and physical performance. Arch Phys Med Rehabil 2006;87: 680-687.

61 Oh-Park M, Fast A, Gopal S: Exercise for the dialyzed: aerobic and strength training during hemodialysis. Am J Phys Med Rehabil 2002;81:814-821.

- 62 Kong CH, Tattersall JE, Greenwood RN, Farrington $\mathrm{K}$ : The effect of exercise during haemodialysis on solute removal. Nephrol Dial Transplant 1999;14:2927-2931. 
-63 Vaithilingam I, Polkinghorne KR, Atkins RC, Kerr PG: Time and exercise improve phosphate removal in hemodialysis patients. Am J Kidney Dis 2004;43:85-89.

64 Lott ME, Hogeman CS, Vickery L, Kunselman AR, Sinoway LI, MacLean DA: Effects of dynamic exercise on mean blood velocity and muscle interstitial metabolite responses in humans. Am J Physiol Heart Circ Physiol 2001;281:1734-1741.

-65 Rus RR, Ponikvar R, Kenda RB, ButurovicPonikvar J: Effect of local physical training on the forearm arteries and veins in patients with end-stage renal disease. Blood Purif 2003;21:389-394.

- 66 Kouidi E, Iacovides A, Iordanidis P: Exercise renal rehabilitation program: psychosocial effects. Nephron 1997;77:152-158.

-67 Ouzouni S, Kouidi E, Sioulis A, Grekas D, Deligiannis A: Effects of intradialytic exercise training on health-related quality of life indices in haemodialysis patients. Clin Rehabil 2009;23:53-63.

-68 Painter P, Carlson L, Carey S, Paul SM, Myll $\mathrm{J}$ : Physical functioning and health-related quality-of-life changes with exercise training in hemodialysis patients. Am J Kidney Dis 2000;35:482-492.

- 69 Frey S, Mir AR, Lucas M: Visceral protein status and caloric intake in exercising versus nonexercising individuals with end-stage renal disease. J Ren Nutr 1999;9:71-77.

-70 Painter P, Stewart AL, Carey S: Physical functioning: definitions, measurement, and expectations. Adv Ren Replace Ther 1999;6: 110-123.

71 Koufaki P, Mercer TH, Naish PF: Effects of exercise training on aerobic and functional capacity of end-stage renal disease patients. Clin Physiol Funct Imaging 2002;22:115124.

72 Johansen KL: Physical functioning and exercise capacity in patients on dialysis. Adv Ren Replace Ther 1999;6:141-148.

73 Cheema B, O'Sullivan A, Chan M: Progressive resistance exercise training during hemodialysis: rationale and method of a randomized-controlled trial. Hemodial Int 2006;10:303-310.

74 Mercer TH, Naish PF, Gleeson, NP, Wilcock JE, Crawford C: Development of a walking test for the assessment of functional capacity in non-anaemic maintenance dialysis patients. Nephrol Dial Transplant 1998;13: 2023-2026.

75 Kouidi E, Albani M, Konstantinos N: The effects of exercise training on muscle atrophy in haemodialysis patients. Nephrol Dial Transplant 1998;13:685-699.

-76 Headley S, Germain M, Mailloux P: Resistance training improves strength and functional measures in patients with end-stage renal disease. Am J Kidney Dis 1998;40:355364
77 Heiwe S, Clyne N, Tollback A, Borg K: Effects of regular resistance training on muscle histopathology and morphometry in elderly patients with chronic kidney disease. Am J Phys Med Rehabil 2005;84:865-874.

78 Cheema B, Abas H, Smith B: Randomized controlled trial of intradialytic resistance training to target muscle wasting in ESRD the Progressive Exercise for Anabolism in Kidney Disease (PEAK) study. Am J Kidney Dis 2007;50:574-584.

79 Chumlea WC: Anthropometric and body composition assessment in dialysis patients. Semin Dial 2004;17:466-470.

80 Sakkas GK, Sargeant AJ, Mercer TH: Changes in muscle morphology in dialysis patients after 6 months of aerobic exercise training. Nephrol Dial Transplant 2003;18:18541861.

81 National Collaborating Centre for Chronic Conditions: Chronic Kidney Disease: National Clinical Guideline for Early Identification and Management in Adults in Primary and Secondary Care. London, Royal College of Physicians, 2008.

82 Johansen KL: Exercise and dialysis. Hemodial Int 2008;12:290-300.

83 Nelson ME, Rejeski WJ, Blair SN: Physical activity and public health in older adults: recommendation from the American College of Sports Medicine and the American Heart Association. Circulation 2007;116: 1094-1105.

84 Van Vilsteren MC, de Greef MH, Huisman RM: The effects of a low-to-moderate intensity pre-conditioning exercise programme linked with exercise counselling for sedentary haemodialysis patients in The Netherlands: results of a randomized clinical trial. Nephrol Dial Transplant 2005;20:141-146.

85 Fuhrmann I, Krause R: Principles of exercising in patients with chronic kidney disease, on dialysis and for kidney transplant recipients. Clin Nephrol 2004;61(suppl 1):14-25.

86 Kouidi E, Grekas D, Deligiannis A, Tourkantonis A: Outcomes of long-term exercise training in dialysis patients: comparison of two training programs. Clin Nephrol 2004; 61(suppl 1):31-38.

87 Banerjee A, Kong CH, Farrington K: The haemodynamic response to submaximal exercise during isovolaemic haemodialysis. Nephrol Dial Transplant 2004;19:15281532 .

88 Johansen KL, Painter PL, Sakkas GK, Gordon P, Doyle J, Shubert T: Effects of resistance exercise training and nandrolone decanoate on body composition and muscle function among patients who receive hemodialysis: a randomized controlled trial. J Am Soc Nephrol 2006;7:2307-2314

89 Pupim LB, Flakoll PJ, Levenhagen D, Ikizler TA: Exercise augments the acute anabolic effects of intradialytic parenteral nutrition in chronic hemodialysis patients. Am J Physiol Endocrinol Metab 2004;286:589-597.
90 Goldberg AP, Hagberg JM, Delmez JA, Heath GW, Harter HR: Exercise training improves abnormal lipid and carbohydrate metabolism in hemodialysis patients. Trans Am Soc Artif Intern Organs 1979;25:431437.

-91 Steiner MC, Morgan MD: Enhancing physical performance in chronic obstructive pulmonary disease. Thorax 2001;56:73-77.

92 Koufaki P, Nash PF, Mercer TH: Assessing the efficacy of exercise training in patients with chronic disease. Med Sci Sports Exerc 2000;34:1234-1241.

93 Malagoni AM, Catizone, L, Mandini S, Soffritti S, Manfredini R, Boari B, Russo G, Basaglia N, Zamboni P, Manfredini F: Acute and long-term effects of an exercise program for dialysis patients prescribed in hospital and performed at home. J Nephrol 2008;21:871-878.

94 Painter P: Exercise for patients with chronic disease: physician responsibility. Curr Sports Med Rep 2003;2:173-180.

95 UK Renal Registry: 11th Annual Report 2008. Bristol, UK Renal Registry, 2008.

$>96$ Koopman R, van Loon LJC: Aging, exercise, and muscle protein metabolism. J Appl Physiol 2009;106:2040-2048.

\$7 Stack AG, Murthy B: Exercise and limitations in physical activity levels among new dialysis patients in the United States: an epidemiologic study. Ann Epidemiol 2008; 18: 880-888.

98 O'Hare A, Johansen K: Lower-extremity peripheral arterial disease among patients with end-stage renal disease. J Am Soc Nephrol 2001;12:2838-2847.

99 Combe C, Albert JM, Bragg-Gresham JL, Andreucci VE, Disney A, Fukuhara S, Goodkin DA, Gillespie BW, Saito A, Jadoul M, Pisoni RL: The burden of amputation among hemodialysis patients in the Dialysis Outcomes and Practice Patterns Study (DOPPS). Am J Kidney Dis 2009;54:680692

100 O'Hare AM, Hsu CY, Bacchetti P, Johansen KL: Peripheral vascular disease risk factors among patients undergoing hemodialysis. J Am Soc Nephrol 2002;13:497-503.

101 European Association of Rehabilitation in Chronic Kidney Disease. http://www/renalrehab.com/indexeng.htm (accessed February 20, 2009).

102 Grubeck-Loebenstein B, Vierhapper H, Waldhäusl W, Korn A, Graf M, Panzer S: Adrenergic mechanisms and blood pressure regulation in diabetes mellitus. Klin Wochenschr 1982;60:823-828.

103 Heffernan KS, Jae SY, Vieira VJ, Iwamoto GA, Wilund KR, Woods JA, Fernhall B: Creactive protein and cardiac vagal activity following resistance exercise training in young African-American and white men. Am J Physiol 2009;296:1098-1105. 


\section{Editorial Comment}

M. El Nahas, Sheffield

The minireview by Kosmadakis and colleagues from the UK reminds nephrologists of a topic that has long been neglected, namely that of the value of exercise in chronic kidney disease/end-stage renal disease (ESRD) patients. They review the evidence for the impact of lack of exercise on outcomes in ESRD patients on replacement therapy. They also examine carefully the potential physical and psychological benefits of aerobic, resistance and flexibility activities in haemodialysis patients. These include possible improved dialysis efficacy and blood pres- sure control. Attention should be paid to tailoring the exercise programme to the patient's capabilities and underlying comorbidities. The authors conclude by calling for a randomized control study to settle the issue of physical inactivity in dialysis patients. Such a trial may be difficult to conduct in view of the case mix of patients on dialysis and the numerous confounders that affect their outcomes; the number of inconclusive clinical trials in dialysis patients is rapidly expanding, highlighting such difficulties. 